\title{
Çocuklar İçin Sağlıklı Yeme Öz-Yeterlik Ölçeğinin Türkçe Geçerlik ve Güvenirlik Çalışması
}

\section{The Turkish Validity and Reliability Study of the Healthy Eating Self-Efficacy Scale for Children}

\author{
Esma KABASAKAL ${ }^{1}$, Umut Ece ARSLAN², Sarp ÜNER², Hande KONŞUK ÜNLÜ², Nazmi BILIR \\ Mahmut Sadi YARDIM${ }^{4}$, Özgür ARAZ ${ }^{5}$, Terry HUANG ${ }^{6}$, Hilal ÖZCEBE ${ }^{4}$
}

\author{
${ }^{1}$ Yıldırım Beyazıt Üniversitesi, Halk Sağlığı Hemşireliği ABD, Ankara, Türkiye \\ ${ }^{2}$ Hacettepe Üniversitesi, Halk Sağlığı Enstitüsü, Sağlık Araştırmaları ABD, Ankara, Türkiye \\ ${ }^{3}$ Halk Sağlığı Profesörü, Ankara Türkiye \\ ${ }^{4}$ Hacettepe Üniversitesi, Tıp Fakültesi, Halk Sağlığı Anabilim Dalı, Ankara, Türkiye \\ ${ }^{5}$ Nebraska Üniversitesi, İşletme Fakültesi-Lincoln, NE,ABD, Nebraska Üniversitesi Tıp Merkezi, Halk Sağlığı Fakültesi, Omaha, NE, \\ ABD \\ ${ }^{6}$ Sistemler ve Toplum tasarımı merkezi, Halk Sağlığı ve sağlık Politikası Enstitüsü, New York City Üniversitesi, ABD
}

\section{Öz}

Amaç: Bu araştırmanın amacı, çocuklarda sağlıklı yiyecek seçimine dair öz-yeterlik düzeyinin belirlenmesini sağlayacak "Çocuklar için Sağlıklı Yeme Öz-Yeterlik Ölçeği'ni Türkçeye uyarlamak, geçerlik ve güvenirliğini belirlemektir.

Gereç ve Yöntemler: Metodolojik nitelikteki bu çalışmada Çocuklar için Sağlıklı Yeme Öz- Yeterlik Ölçeği'nin Türkçe sürümünü uyarlama, geçerlik ve güvenirlik çalışması yapılmıştır. Ölçeğin dil eşdeğerliği yapılmıştır. Ölçek, Ankara ilinde üç farklı sosyo ekonomik düzeyden seçilen altı okulda 613 öğrenci üzerinden değerlendirilmiştir. Ölçeğin yapı geçerliği açıklayıcı faktör analizi ve doğrulayıcı faktör analizi ile, güvenirliği test tekrar test korelasyon katsayısı kullanılarak ve iç tutarlığı Cronbach's alpha katsayısı ile değerlendirilmiştir. Ölçek orjinalinde 8-10 yaş grubu kız çocuklarında geliştirilmiş olup bu çalışmada ilköğretim 4.sınıf öğrencileri üzerinde uygulanmıştır.

Bulgular: Ölçek tek boyut 9 maddeden oluşmuştur. Ölçeğin orijinalinde Cronbach's alpha değeri 0.62'dır. Bu çalışmada, ölçeğin test-tekrar test güvenirliği hem erkek (rho=0.541, $p<0.01$ ) hem de kız (rho=0.553, p<0.01) çocukları için kabul edilebilir düzeydedir. Ölçek her iki cinsiyet grubu için de iyi bir iç tutarlı̆ğa sahiptir (erkek çocuklar için: a=0.677 ve kız çocuklar için: $a=0.674)$.

Sonuç: Ölçeğin analiz sonuçları orijinal yapıya uyum sağladığı için ölçeğin Türkçe uyarlamasının geçerli ve güvenilir olduğu söylenebilir.

Anahtar Sözcükler: Çocuk, Geçerlik ve güvenirlik, Ölçek, Öz-yeterlik, Sağlıklı yeme

(1)

KABASAKAL E

ARSLAN UE

ÜNER S

KONSUKK ÜNLÜ H

KONSSUK
BILIRN

YARDIM MS

ARAZ Ö

HUANG T

ÖZCEBE

Çıkar Çatışması / Conflict of Interest: Tüm yazarlar adına, sorumlu yazar çıkar çatışması olmadığını belirtir.

0000-0001-9305-4363 0000-0002-0884-8079 :0000-0002-9880-8811 :0000-0002-9880-8811 $0000-0002-9285-1835$ 0000-0002-9285-1835 0000-0003-2951-2301 0000-0001-5544-5187 0000-0002-0918-8519

Committee Approval: Bu calısmada ulusal ve uluslararası etik kurallara uyulmuștur. Bu çalısmanın yapılması Hacettepe Universitesi Girișimsel Olmayan Etik Kurulu tarafından onaylanmıștır (GO 14-429-07) ve III Milli Eğitim Müdürlüğü ve okul yönetiminden idari izin alınmıștır

Yazarların katkısı / Contribution of the Authors: KABASAKAL E: Araştırma ve/veya makalenin hipotezini veya fikrini oluşturan, Çalıșma için gerekl teratür taramasında sorumluluk almak, Çalısmanın bütününün veya önemli bölümlerinin yazımında sorumluluk almak. ARSLAN UE: Arastırma ve/

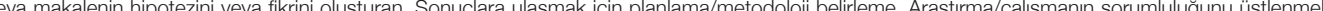
mini denetlemek, Hasta takibinde sorumluluk almak, ilg lob Sonuçların mantıksal olarak Yorumlanması ve sonuçlandırıması, Çalıșma için gerekli literatur taramasına sorumluluk almak, Çalışmanı bưtũnünün veya önemli bölümlerinin yazımında sorumluluk almak. ÜNER S: Ảraştırma ve/veya makalenin hipotezini veya fikrini oluşturan, Sonuçlara ulaşmak için planlama/metodoloji belirleme, Araşıırma/çalışmanın sorumluluğunu üstlenmek, ilerlemenin seyrini denetlemek, Hasta takibinde sorumluluk almak, ilgill biyolojik malzemelerin toplanması, veri yönetimi ve raporlama, deneylerin yürütülmesi, Sonuçların mantıksal olarak Yorumlanması ve sonuçlandırılması, Çalıșmanın bütününün veya önemli bölümlerinin yazımında sorumluluk almak. KONȘUK ÜNLU H: Araștırma ve/veya makalenin hipotezini veya fikrini olușturan, Sonuçlara ulașmak için planlama/metodoloji belirleme, Araștırma/çalıșmanın sorumluluğunu üstlenmek, ilerlemenin seyrini denetlemek, Hasta ma veya makalenin hipotezini veya fikrini olusturan. YARDIM MS: Araștırma ve/veya makalenin hipotezini veya fikrini olușturan, Sonuçlara ulașmak için planlama/metodoloji belirleme, Araștırma/çalıșmanın sorumluluğunu üstlenmek, ilerlemenin seyrini denetlemek, Hasta takibinde sorumluluk almak, ilgili biyolojik malzemelerin toplanması, veri yönetimi ve raporlama, deneylerin yürütülmesi, Sonuçların mantıksal olarak Yorumlanması ve sonuçlandırılması. ARAZ Ö: Araștırma ve/veya makalenin hipotezini veya fikrini olușturan, Sonuçların mantıksal olarak Yorumlanması ve sonuçlandırılması, Çalıșmanın bütününün veya önemli bölümlerinin yazımında sorumluluk almak. HUANG T: Araștırma ve/veya makalenin hipotezini veya fikrini olușturan, Sonuçlara ulașmak için planlama/metodoloji belirleme, Sonuçların mantıksal olarak Yorumlanması ve sonuclandırılması, Calıșma için gerekli literatür taramasında sorumluluk almak, Calışmanın bütününün viönemli bölümlerinin yazimnda sorumluluk almak Yazm ve dibilgisi disında bilimsel olarak gönderilmeden belirleme, Sonuçların mantıksal olarak Yorumlanması ve sonuçlandırıması, Calıșma için gerekli literatür taramasında sorumluluk almak, Çalıșmanın bütününün veya önemli bölümlerinin yazımında sorumluluk almak, Yazım ve dilbilgiși dışında bilimsel olarak gönderilmeden önce makaleyi gözden geçirme

Atıf yazım sekli / How to cite : Kabasakal E, Arslan UE, Üner S, Konșuk Ünlü H, Bilir N, Yardım MS ve ark. Çocuklar Için Sağıklı Yeme Öz-Yeterlik Ölçeğinin Türkçe Geçerlik ve Güvenirlik Çalıșması. Türkiye Çocuk Hast Derg 2021;15: 72-77.

Yazışma Adresi / Correspondence Address:

Esma KABASAKAL

Yildirim Beyazit University, Nursing Department,

Public Health Nursing Deparment Ankara, Turkey

E-posta: esm.akf@gmail.com
Geliș tarihi / Received : 19.04.2019

Kabul tarihi / Accepted : 31.12.2019

Elektronik yayın tarihi $\quad$ : 24.03.2020

Online published

DOI: 10.12956/tchd.556078 


\section{ABSTRACT}

Objective: The aim of this study is to adapt the Healthy Eating Self-Efficacy for Children Scale to Turkish and determine its reliability and validity.

Material and Methods: It was performed adaptation, validity and reliability study of the Healthy Eating Self- Efficacy for Children Scale Turkish version in this methodological study. The scale was evaluated after the scale's seven-stage language equivalence study, with 613 students in six schools selected from three different socioeconomic levels. In the validity study, scale were evaluated explanatory factor analysis and confirmatory factor analysis for construct validity, test-retest for reliability assessment and Cronbach analizs alpha coefficient for internal consistency. The scale was originally developed in girls aged between 8 and 10 years.

Results: Scale consisted of 9 items. The original Cronbach's alpha of the scale was 0.62 . In this study, test-retest reliability of the scale was acceptable range for both boys ( $r h o=0.541, p<0.01$ ) and girls ( $r h o=0.553, p<0.01$ ). There was good internal consistency for both gender ( $\mathrm{a}=0.677$ for boys and $\mathrm{a}=0.674$ for girls)

Conclusion: As a conclusion, Turkish version of the scale was valid and reliable.

Key Words: Child, Validity and reliability, Scale, Self-efficacy, Healthy eating

\section{GiRiş}

Beslenme sağlığın temel koşulu olup, sağlıksız beslenme hastalıkların nedenleri arasında önsıralarda yer almaktadır (1). Okul çağı çocukları, büyüme ve gelişme süreçleri nedeniyle yeterli ve dengeli beslenme açısından hassas bir grubu oluşturmaktadırlar (2). Sağlıkı beslenme, çocuklarda büyüme ve gelişmenin yanı sıra bilişsel kapasiteyi ve başarıyı artırmaktadır. Sağlıksız beslenme ve buna bağı ortaya çıkan hastalıklar, çocuğun hastalık yükünü artırdığı gibi öğrenme potansiyelinde azalmaya neden olmaktadır. Yeterli ve dengeli beslenmesi olan çocuklar, okul içerisinde daha dikkatli, özenli olup öğrenim sürecinde daha bașarılı ve fiziksel olarak daha aktiftirler (3). Yine sağlıklı beslenme, yaşam kalitesinin yükselmesini sağlamaktadır (4). Beslenme alışkanlıkları, çocukluk döneminden itibaren kazanılımaya başlanmaktadır. Bu dönemde kazanılan beslenme alışkanlıkları, erișkin dönemde devam edebilmektedir (5). Bu nedenle çocukluk döneminde sağ|ıkı yeme davranışlarının kazandırıması önemlidir. Literatüre göre okul çağı çocukları önerilen miktarda meyve ve sebze tüketmemekte, buna karşın enerji, yağ ve tuz içeriği fazla olan hazır yiyecek ve enerji içeceklerini, abur cuburu sık tüketmektedirler $(6,7)$. Türkiye'de yapılan araştırmalara göre; çocukların önemli bir oranının kahvaltı yapmadığı, okulda sıklıkla simit ve bisküvi tükettikleri doymuş yağ, tuz ve kolesterolü fazla; meyve sebze ve temel besin gruplarını önerilenden az tükettikleri belirtilmiştir (8-11). Çocuklarda sağlıklı beslenme bilincinin geliştirilmesi ve beslenme davranışlarını etkileyen çoklu etkileşimli faktörlerin anlaşımasını gerektirir (12). Bu bağlamda öz-yeterlik pek çok sağlık davranışının açıklanmasında önemli bir role sahiptir ve beslenme alışkanlıklarının güçlü bir belirleyicisi olarak gösterilmektedir (13). Öz-yeterlik bireyin bir davranışı yapabileceğine dair kendine olan güvenini ifade etmektedir (14). Sağlıklı yeme öz-yeterliği ise bireyin daha sağlıklı yiyecekleri seçme ve tercih etmesine ilişkin algllanan yeterlik düzeyidir. $\mathrm{Bu}$ nedenle sağlıkı beslenmenin değerlendirilmesinde ele alınması gereken bir göstergedir (15). Literatür bulgularına göre çocuklarda beslenme öz-yeterlik düzeyi, çocuğun beslenme alıskanlıkları ve beden kitle indeksi değerlerinin bir belirleyicisidir (16-18). Bu bağlamda çocukların sağlıkı beslenme davranışı kazanmalarını sağlamak ve sağlıkı besin tüketimini artırmak için öz-yeterlik düzeylerinin belirlenmesi gerekir. Bu amaçla yapılmış uygun ölçme aracı olarak Story ve ark.(19) tarafindan geliştirilen "Healthy Eating Self Efficacy Scale" oldukça yaygın kullanılan bir ölçme aracıdır. Bu araştırmada "Çocuklar İçin Sağlıklı Yeme Öz-Yeterlik Ölçeği” şeklinde çevirisi yapılan bu ölçeğin Türkçe konuşulan toplumlar için Türkçeye uyarlanması, geçerlilik ve güvenilirlik çözümlemelerinin yapılması amaçlanmıştır. Bu sayede çocukların sağlıkı yeme öz yeterlik düzeylerini saptayabilecek Türkçe geçerli ve güvenilir bir ölçme aracı uyarlanmış olacaktır. Böylece çocukların sağlıkı yiyecekler seçimindeki isteklilikleri belirlenmiş olacak ve bu doğrultuda çocuklarda sağlıkı yeme davranışı kazandırma faaliyetlerinin planlanması kolaylaşacaktır.

\section{GEREÇ ve YÖNTEMLER}

Story ve ark.(19) tarafından geliştirilen ölçeğin orijinal adı "SelfEfficacy for Healthy Eating"dir. Ölçek çocukların sağliklı yeme için öz yeterliliğinin değerlendirmesinde kullanılmak amacıyla 8-10 yaș grubu kIz çocukları üzerinde geliștirilmiștir. Ölçek 9 maddeden ve tek boyuttan oluşan üçlü likert tipi bir ölçektir. Ölçeğin Cronbach's alpha değeri 0.62'dir.Ölçeğin Türkçe'ye uyarlanmış adı "Çocuklar İçin Sağlıklı Yeme Öz-Yeterlik Ölçeği” dir. Ölçek "Çocukluk Döneminde Şișmanlık, Ailelerin Algısı ve Yaklaşımı (Proje No: TUA-2015-5521)" çalışması kapsamında 2015 ylında uyarlanmıştır. Ölçeğin dil eşdeğerliği uyarlama çalışmasında aşamalı bir yöntem kullanımıştır. Ölçeğin Türkçeye çevrilmesi, araştırmacılar tarafından yapıımıștır. Araştırmacılar Türkçe ve İngilizceyi iyi düzeyde bilmektedirler. Türkçe çevirisi yapılan ölçek sağlık profesyonelleri (halk sağlığı ve diğer sağllk profesyonelleri) ve Türkçe uzmanları (Türkçe öğretmenleri ve Türk dili ve Edebiyatı uzmanları) tarafından kültürel uyumu açısından değerlendirilmiştir. Tekrar düzenlenen ölçeğin ön denemesi yapılmıștır. Ön deneme așamasında 20 çocuk ve ailesine ulașılmıștır. Ön deneme sırasında alınan görüşler doğrultusunda tekrar düzenleme yapılmış ve beş Türkçe uzmanı (Türkçe öğretmeni, Türk Dili ve Edebiyatı uzmanı) tarafından dil geçerliği yapılmıştır. Ölçek profesyonel ve tarafsız bir grup tarafindan tekrar İngilizceye çevrilmiștir. 
İngilizce anadile sahip olan bir grup tarafindan, original ölçek ve uyarlanan ölçek karşılaştırımış ve uyumlu bulunmuştur (Ek 1).

Bu çalışmanın yapılması Hacettepe Üniversitesi Girişimsel Olmayan Etik Kurulu tarafindan onaylanmışıı (GO 14-42907) ve II Milli Eğitim Müdürlüğü ve okul yönetiminden idari izin alınmıştır. Türkçe formunun geçerlik/güvenirlik çalışması, Ankara'da altı okulda 4. Sınıf öğrencileriyle yürütülmüştür. Araştırma sırasında ulaşılan 641 öğrenciden 613'ü çalıșmada ( $n=328, \% 53.5$ erkek ve $n=285 \% 46.5$ kız) yer almıştır. Okullar üç farklı sosyoekonomik düzeyden ( $n=231, \% 37.7$ düşük; $n=196$, \%32 orta; n=186, yüksek \%30.3) seçilmiştir. Test tekrar-teste toplam 508 öğrenci ( $n=270, \% 53.1$ erkek ve $n=238 \% 46.9$ kı) katılmışıı. Okulların sosyoekonomik düzeylerine göre katıım ise şu şekildedir: düşük sosyoekonomik düzeyde 163 öğrenci (\%32.1), orta sosyoekonomik düzeyde 182 öğrenci (\%35.8) ve yüksek sosyoekonomik düzeyde 163 öğrenci (\%32.1). Ölçek uygulaması gözlem altında anket uygulama tekniği kullanılarak yapılmıştır. Ölçekte toplam dokuz soru bulunmaktadır. Sağlıklı besinleri tercih etmesine yönelik tercihlerini sorarak, tercih etme düzeyi sorulmaktadır. Her soru için "hiç zor değil", "biraz zor" ve "çok zor" seçenekleri yer almaktadır. Ölçeğin değerlendirilmesi sırasında işaretlenen her "Hiç zor değil" seçeneği için 0 puan, işaretlenen her "Biraz zor" seçeneği için 1 puan ve işaretlenen her "Çok zor" seçeneği için 2 puan olacak şekilde tüm maddeler alınan puanlar toplanmaktadır. Ölçekte katılımclar 0 ile 18 arasında puan alabilirler. Ters kodlanan ölçek maddesi bulunmamaktadır. Ölçek puanının artması, sağlıklı yeme için özyeterliliğin daha da artıı̆ını göstermektedir.

\section{BULGULAR}

Ölçeğin geçerlik ve güvenirlik analizleri hem erkek hem de kIz çocukları için yapılmıştır. Erkek çocuklarda yapılan temel bileşenler analiz sonuçlarına göre; özdeğer=2.581, açılkanan varyans \%28.680, Kaiser-meyer-olkin (kmo) testi sonucu 0.77 ve Barkett testi sonucu $338.86(p<0.001)$ olarak bulunmuştur (Tablo I). Erkek çocuklar için test-tekrar test Spearman's rho=0.541, ve ölçeğin iç tutarllığı Cronbach's alpha $=0.677$ bulunmuştur (Şekil 1). Kız çocuklarda yapılan temel bileșen analiz sonuçlarına göre öz değer= 2.574, açıklanan varyans \%28.602, Kaiser-meyer-olkin ( $\mathrm{kmo})$ testi sonucu 0.727 ve Barkett testi sonucu 367.495 ( $p<0.001)$ olarak bulunmuştur (Tablo II). KIZ çocuklar için Test tekrar test Spearman's rho=0.553ve ölçeğin iç tutarlıı̆ı Cronbach's alpha=0.674 bulunmuştur (Şekil 2).

Geçerlik ve güvenirlik yapılan araştırma grubunda sosyoekonomik düzeye göre Sağlıkl yeme öz-yeterlik ölçeği sonuçları arasında istatistiksel açıdan anlamlı bir fark yoktur.

Tablo I: Erkek çocuklar için sağlıkı yeme öz-yeterlik ölçeğinin açıklayııı faktör analizi sonuçları.

\begin{tabular}{|l|l|}
\hline & Boyut \\
\hline 7. Cips yerine daha az yağlı kraker yemek & 0.685 \\
\hline 8. Gazıı içecekleri daha az içmek & 0.680 \\
\hline 5. Büyük boy yerine küçük boy patates kızartması seçmek & 0.572 \\
\hline $\begin{array}{l}\text { 6. Patates kızartması, cips, kek, kurabiye veya dondurma gibi fazla miktarda yağ içeren yiyeceklerden } \\
\text { daha az miktarda yemek }\end{array}$ & 0.547 \\
\hline 9. Meyveli gazsız içecekleri (oralet, lezzo vb.) daha az içmek & 0.506 \\
\hline 1. Okul sonrası ara öğünde meyve yemek & 0.466 \\
\hline 2. Ara öğünde sebze yemek & 0.460 \\
\hline 3. Susayınca, gazlı içecekler veya meyveli gazsız içecekler yerine su içmeyi tercih etmek & 0.413 \\
\hline 4. Tam yağlı süt yerine az yağlı veya yağsız süt içmek & 0.409 \\
\hline
\end{tabular}

Tablo II: Kız çocuklar için sağlıklı yeme öz-yeterlik ölçeğinin açıklayıcı faktör analizi sonuçları.

8. Gazlı içecekleri daha az içmek

6. Patates kızartması, cips, kek, kurabiye veya dondurma gibi fazla miktarda yağ içeren yiyeceklerden daha az miktarda yemek 
Tablo III: Öğrencilerin sosyoekonomik düzey ve cinsiyetlerine göre Sağlıklı yeme öz-yeterlikölçeğinin puan dağlımı.

\begin{tabular}{l|c|c|c|c|c|c|c}
\hline & $\mathbf{n}$ & Ortalama & SS & Ortanca & $\begin{array}{c}\text { En } \\
\text { Küçük }\end{array}$ & $\begin{array}{c}\text { En } \\
\text { Büyük }\end{array}$ & $\mathbf{p}$ \\
\hline $\begin{array}{l}\text { Sosyoekonomik Düzey } \\
\text { Düşük }\end{array}$ & 231 & 12.0 & 2.8 & 11.0 & 9.0 & 22.0 & 0.23 \\
$\quad \begin{array}{l}\text { Orta } \\
\text { Yüksek }\end{array}$ & 196 & 11.9 & 2.9 & 11.0 & 9.0 & 20.0 & \\
$\begin{array}{l}\text { Cinsiyet } \\
\text { Erkek }\end{array}$ & 186 & 12.3 & 2.9 & 12.0 & 9.0 & 24.0 & \\
$\quad$ KIz & & & & & & & \\
$\quad$ Toplam & 328 & 12.3 & 2.9 & 12.0 & 9.0 & 24.0 & 0.02 \\
\hline & 285 & 11.8 & 2.7 & 11.0 & 9.0 & 22.0 & \\
\hline
\end{tabular}

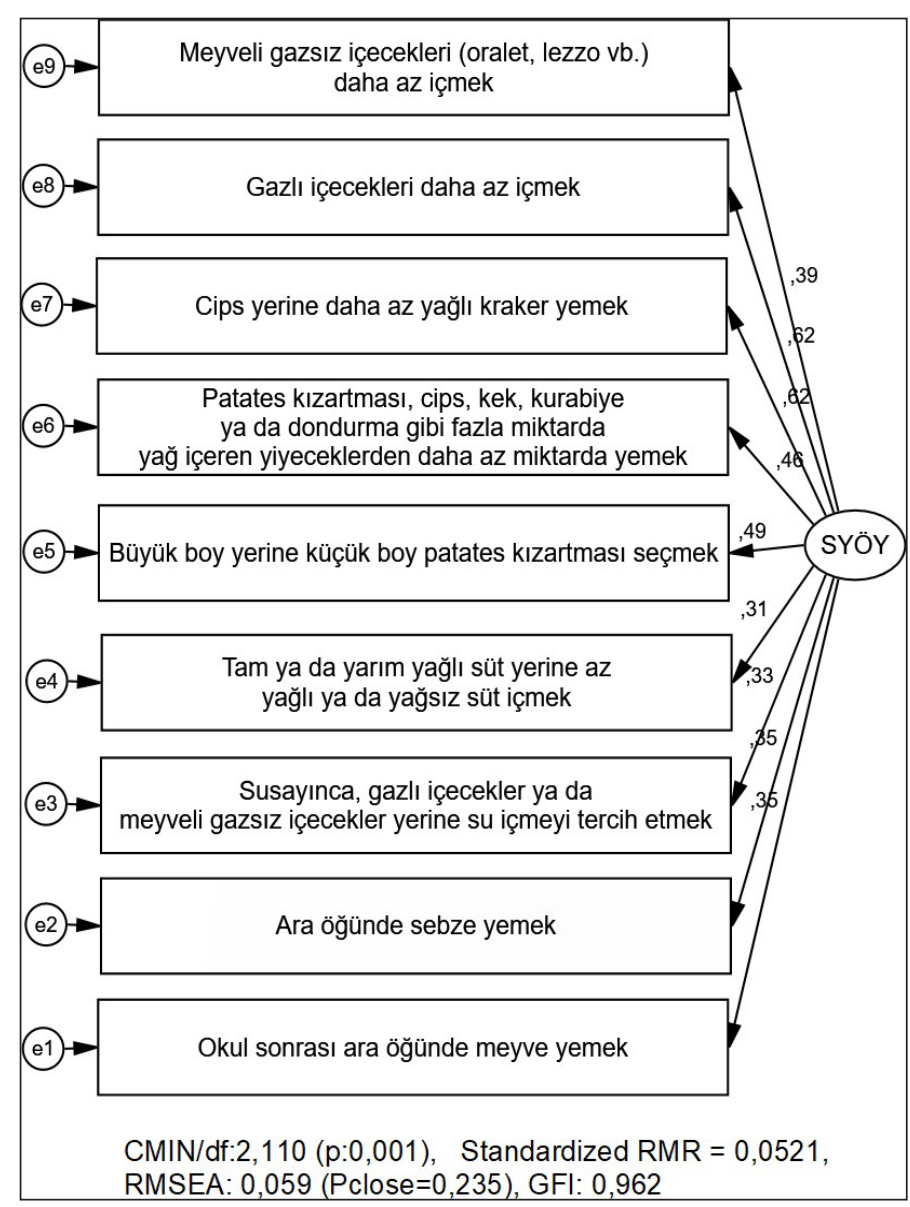

Şekil 1. Erkek çocuklar için sağlıklı yeme öz-yeterlik ölçeği doğrulayıcı faktör analizi sonuçları

Çocukların cinsiyetlerine göre Sağlıklı yeme öz-yeterlik ölçeği puanları arasında anlamlı bir fark bulunmuştur. Buna göre kızlarda Sağlıklı yeme öz-yeterlik ölçeği puanı erkeklere göre daha düşüktür (Tablo III).

\section{TARTIŞMA}

Sağ|lklı yeme öz-yeterlik ölçeğinin (SYÖYÖ-Ç) orijinali 9 madde ve tek boyuttan oluşmaktadır, Türkçe adaptasyonunda aynı yapı korunmuştur. Ölçeğin orijinali, kız çocuklarla geliştirilmiştir. Türkçe uyarlanma çalışması kız ve erkek çocuklar için yapıImıştır.

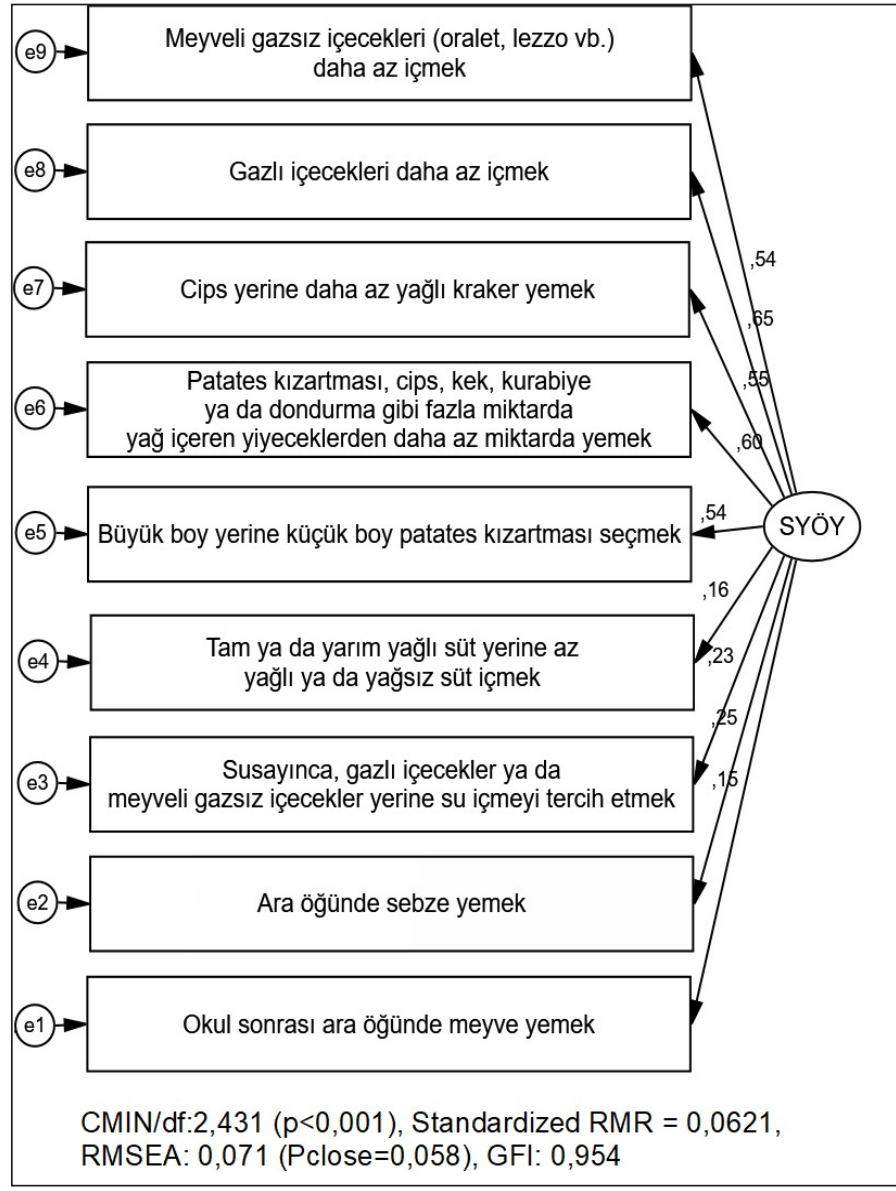

Şekil 2: Kız çocuklar için sağlıklı yeme öz-yeterlik ölçeği doğrulayıcı faktör analizi sonuçları

SYÖYÖ-Ç Açıklayıcı Faktör Analizi (AFA) sonucunda, Özgün ölçeğin tek boyutuna benzer bir dağılım elde edilmiştir. KaiserMeyer-Olkin (KMO) örneklem yeterliği ölçümü sonucuna göre erkekleriçin 0.77 ve kızlar için 0.727 bulunmuştur. İstatistiki olarak $\mathrm{KMO}$ değeri, 0.7-0.8 arasında ise 'iyi' olarak yorumlanmaktadır; bizim sonuçlarımıza göre hem erkekler hem de kızlar için örneklem büyüklüğü "iyi” olarak değerlendirilmektedir (20). SYÖYÖ-Ç alt boyutun açıklanan varyans oranı erkek çocuklar için \%28.680 ve öz değeri 2.581 olarak bulunmuştur. KIz çocukları için açıklanan varyans oranı 28.602 ve öz değeri 2.574 olarak bulunmuştur. Bu araștırmada doğrulayıcı faktör analizi sonuçlarına göre; hem erkek 151 (CMIN/df= 2.110 (p:0.001), 
Standardized RMR $=0.0521, \mathrm{RMSEA}=0.059$ (Pclose $=0.235)$, $\mathrm{GFI}=0.962)$ hem de $\mathrm{kIz} \quad(\mathrm{CMIN} / \mathrm{df}=2.431 \quad(\mathrm{p}<0.001)$, Standardized RMR $=0.0621$, RMSEA $=0.071$ (Pclose $=0.058$ ), $\mathrm{GFI}=0.954)$ çocukları için ölçeğin uyumu iyi düzeydedir (21, 22). Test- tekrar test için hesaplanan Spearman's rho korelasyon katsayllarına göre hem erkek ( $r h o=0.541, p<0.01$ ) hem de kIz (rho=0.553, p<0.01) çocuklar için ölçeğin güvenirliğinin kabul edilebilir düzeyde olduğu söylenebilir (23). Ölçeğin iç tutarlığı için hesaplanan Cronbach alpha katsayılarına göre; hem kız $(a=0.677)$ hem de erkek $(a=0.674)$ çocuklar için kabul edilebilir düzeydedir ve en az özgün ölçek kadar iyi sonuçlar alınmıştır (24-26). Özgün ölçeğin Cronbach alfa katsayısı 0.62'dir (19).

\section{Çalışmanın Sınırlılıkları}

Bu araştırma, Ankara'da 3 farklı sosyoekonomik düzeyde 6 okulun 4. Sınıf öğrencileriyle yapılmışıı. Diğer yaş gruplarına ilişkin yorum yapabilmemiz mümkün değildir. Ayrıca, çalışmanın sadece Ankara'da yapılması da bir sınırllık olarak kabul edilebilir. $\mathrm{Bu}$ tür çalışmaların sınırlıklarından biri de karşılaştıılabilir altın standardın olmamasıdır. Bizim çalışmamızda da ölçeği karşılaştırabilecek bir altın standart yoktur.

\section{SONUÇ}

SYÖYÖ-Ç çocukların sağlıklı yeme öz-yeterlik düzeyini ölçmek üzere 9 maddelik 1 alt boyuttan oluşmaktadır (Ek 1). Bu boyuttan üretilen faktörler açısından araştırmamız özgün araştırma ile benzerlik göstermiştir. SYÖYÖ-Ç Türk toplumunda bu örneklem grubu için geçerli ve güvenilir bir ölçek olarak başka çalışmalarda kullanılabilir.

\section{KAYNAKLAR}

1. WHO, Healthy Diet Key Facts. 2015 https://www.who.int/nutrition/ publications/nutrientrequirements/healthydiet_factsheet 394.pdf Erişim Tarihi: 06.04.2019

2. Khodaee GH, Emami Moghadam Z, Khademi G, Saeidi M. Healthy Diet in Children: Facts and Keys. Int J Pediatr 2015;3:31183-94.

3. Rose-Jacobs R, Black MM, Casey PH, Cook JT, Cutts DB, Chilton $\mathrm{M}$, et al. Household food insecurity: associations with at-risk infant and toddler development. Pediatrics 2008;121:65-72.

4. Baranowski T, Cullen KW, Baranowski J. Psychosocial correlates of dietaryintake: Advancing dietary intervention. Annu Rev Nutr 1999;19:17-40.

5. Özcebe H. Çocuklarda Şişmanlık Salgını. Turkiye Klinikleri J Public Health-Special Topics 2015;1:79-83.

6. Yılmaz SK, Özel HG. Okul Çağı Çocuklarda Şekerli lç̧ecek Tüketimi ile Obezite Riski Arasındaki llişki. Bes Diy Derg 2016;44:3-9.

7. Savaşhan Ç, Erdal M, Sarı O, Aydoğan Ü. Illkokul çağındaki çocuklarda obezite görülme sıklığı ve risk faktörleri. Türkiye Aile Hekimliği Dergisi 2015;19:14-21.

8. Öztürk C, Dicle A, Sarı HY, Bektaş M. Okul dönemindeki çocukların sağlık durumlarının belirlenmesi. Milli Eğitim Dergisi 2004;163.
9. Özcebe, H., Bağcı-Bosi, A. T., Yardım, M. ve Yardım, N. Türkiye Çocukluk Çağı (llkkokul 2. Sınıf Öğrencileri) Şişmanlık Araştırması COSI-TUR 2017, Ankara: Efe Matbaacilık.

10. Baş M, Altan T, Dinçer D, Aran E, Kaya HG, Yüksek O. Determination of dietary habits as a risk factor of cardiovascular heart disease in Turkish adolescents. Eur J Nutr 2005;44:174-82.

11. Öner N, Vatansever Ü, Sarı A, Ekuklu G, Güzel A, Karasalihoglu S. Prevalence of underweight, overweight and obesity in Turkish adolescents. Swiss Med Wlky 2004;134:529-33.

12. McClain AD, Chappuis C, Nguyen-Rodriguez ST, Yaroch AL,SpruijtMetz D. Psychosocial correlates of eating behavior in children and adolescents: A review. The Int J Behav Nutr Phys Act 2009;6:54.

13. Rinderknecht K, Smith C. Social cognitive theory in an after-school nutrition intervention for urban Native American youth. J Nutr Educ Behav 2004;36:298-304.

14. Bandura A. Social cognitive theory: an agentic perspective. Annu Rev Psychol 2001;52:1-26.

15. Berman ES. The relationship between eating self-efficacy and eating disorder symptoms in a non-clinical sample. Eat Behav 2006;7:799.

16. Ha SA, Lee SY, Kim KA, Seo JS, Sohn CM, Park HR, et al. Eating habits, physical activity, nutrition knowledge, and self-efficacy obesity status in upper-grade elementary school students. Nutr Res Pract 2016;10:597-605.

17. Rabiei L, Sharifirad GR, Azadbakht L, Hassanzadeh A. Understanding the relationship between nutritional knowledge, self-efficacy, and self-concept of high- school students suffering from overweight. J Educ Health Promot 2013;2:39.

18. O'Dea JA, Wilson R. Socio-cognitive and nutritional factors associated with body massindex in children and adolescents: possibilities for childhood obesity prevention. Health Educ Res 2006;21:796-805.

19. Story M, Sherwood NE, Himes JH, Davis M, Jacobs DR, Cartwright $\mathrm{Y}$, et al. An after-school obesity prevention program for African-American girls: the Minnesota GEMS pilot study. Ethn Dis 2003;13:54-64.

20. Aktürk Z, Acemoğlu H. Tıbbi araştırmalarda güvenilirlik ve geçerlilik. Dicle Tıp Dergisi 2012;39:316-9.

21. Hooper D, Coughlan J, Mullen M. Structural equation modelling: guidelines for determining model fit. EJBRM 2008;6:53-60

22. Feinian Chen F, Curran PJ, Bollen KA, Kirby J, Paxton P. An empirical evaluation of the use of fixed cutoff points in RMSEA test statistic in structural equation models. Sociol Methods Res 2008;36:462-94.

23. Schober P, Boer C, Schwarte LA. Correlation Coefficients: Appropriate Use and Interpretation. Anesth Analg 2018;126:17638.

24. Hume C, Ball K, Salmon J. Development and reliability of a selfreport questionnaire to examine children's perceptions of the physical activity environment at home and in the neighborhood. Int J Behav Nutr Phys Act 2006;3:16.

25. Sim J, Wright C. Research in health care: concepts, designs and methods. 1st ed. United Kingdom, Stanley Thornes Publishers 2000.

26. Horne R, Hankins M, Jenkins R. The Satisfaction with Information about Medicines Scale (SIMS): a new measurement tool for audit and research. Qual Health Care 2001;10:135-40. 
EK-1: Çocuklar İçin Sağ|lık Yeme Öz-Yeterlik Ölçeği

Yönerge: Aşağıdaki sorular senin yeme alıșkanlıkların ile ilgilidir.

Bazı yiyeceklerden daha az, bazı yiyeceklerden ise daha fazla tüketmenin senin için ne kadar zor olduğunu düşünüyorsun?

1) Okul sonrası ara öğünde meyve yemek

Hiç zor değil Biraz zor

Çok zor

2) Ara öğünde sebze yemek

3) Susayınca, gazlı içecekler ya da meyveli gazsız içecekler yerine su içmeyi tercih etmek

4) Tam ya da yarım yağlı süt yerine az yağlı ya da yağsız süt içmek

5) Büyük boy yerine küçük boy patates kızartması seçmek

6) Patates kızartması, cips, kek, kurabiye ya da dondurma gibi fazla miktarda yağ içeren yiyeceklerden daha az miktarda yemek

7) Cips yerine daha az yağlı kraker yemek

8) Gazlı içecekleri daha az içmek

9) Meyveli gazsız içecekleri (oralet, lezzo vb.) daha az içmek 